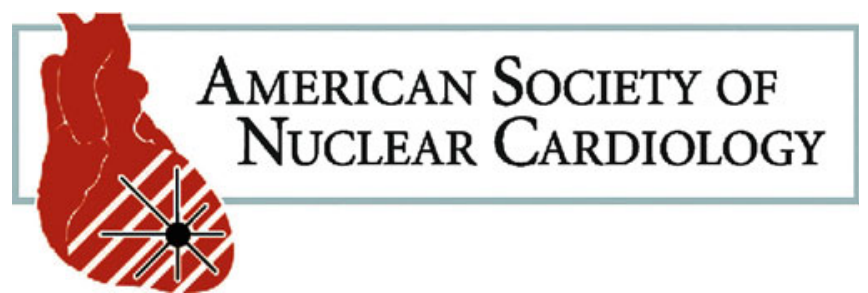

\title{
ASNC CALENDAR
}

\section{CALENDAR}

Please note that the programs listed below are sponsored or cosponsored by the American Society of Nuclear Cardiology (ASNC). For more information, visit the ASNC Web site (http://www.asnc.org/event.cfm).

January 20-22, 2012. Advances in Nuclear Cardiology and Cardiac CT: 27th Annual Case Review with the Experts. Los Angeles, CA.

April 15-17, 2012. Nuclear Cardiology for the Office-Based Practice. Philadelphia, PA.

May 4-6, 2012. Nuclear Cardiology for the Technologist. Chicago, IL.

July 27-29, 2012. Nuclear Cardiology Board Exam Preparation Course. Chicago, IL.
September 5-6, 2012. Nuclear Cardiology Board Exam Preparation Course. Baltimore, MD.

September 5-6, 2012. Nuclear Cardiology for the Working Technologist. Baltimore, MD.

September 6-9, 2012. ASNC2012: The 17th Annual Scientific Session of the American Society of Nuclear Cardiology. Baltimore, MD.

ASNC also offers many online resources for busy professionals, including a new Webinar series, Meetings on Demand, and the Journal of Nuclear Cardiology CME. Visit www.asnc.org to learn more. 